Volume 8. No. 9, September 2020

International Journal of Emerging Trends in Engineering Research

Available Online at http://www.warse.org/IJETER/static/pdf/file/ijeter211892020.pdf

https://doi.org/10.30534/ijeter/2020/211892020

\title{
Determination of Requirements for Protection of Radio-Electronic Means of Security Management of Particularly Important State Energy Facilities from the Destructive Impact of Electromagnetic
}

\author{
Oleksandr Akimov ${ }^{1}$, Marta Karpa ${ }^{2}$, Clavdia V. Dubych ${ }^{3}$, Diana Zayats ${ }^{4}$, Nataliia Movmyga ${ }^{5}$, Natalia Tverdokhliebova ${ }^{5}$ \\ ${ }^{1}$ The Department of Public Administration, Interregional Academy of Personnel Management, Ukraine, \\ maxnik8888@gmail.com,1970aaa@ukr.net \\ ${ }^{2}$ The Department of Management and Business Administration, Vasyl Stefanyk Precarpathian National University, Ukraine, \\ marta.karpa@ukr.net \\ ${ }^{3}$ The Department of Public Administration, Institute for Personnel Training of the State Employment Service of Ukraine, Ukraine, \\ kdubych@ukr.net \\ ${ }^{4}$ The Department of Regional Management and Local Self-Government, The Lviv Regional Institute of Public Administration of the \\ National Academy of Public Administration, the President of Ukraine, Ukraine, \\ dianazaj22@gmail.com \\ ${ }^{5}$ The Department of the Occupational and Environmental Safety, National Technical University "Kharkov Polytechnic Institute", Ukraine, \\ movnat@bigmir.net, natatv@ukr.net
}

\begin{abstract}
The article considers the issues of protection of electronic means from the destructive effects of electromagnetic radiation created by terrorist means of electromagnetic effects. The basic requirements to means of protection which are realized on the basis of use of nature-like technologies are defined.

Possible variants of influence on radio electronic means (REM) are considered. Requirements for means of protection of electronic means against destructive electromagnetic influence created by terrorist means are defined.

The necessity of protection of REM of especially important state objects from the destructive electromagnetic influence created by terrorist means by means of means of protection on the basis of use of the nature-like technologies is proved.
\end{abstract}

Key words: Radio electronic means, electromagnetic radiation, ultrashort pulse duration, plasma protection technologies, gaseous plasma media.

\section{INTRODUCTION}

At present, with the advent of new information technologies, solving problems of increasing the capacity of strategic energy facilities, expanding energy supply systems, protection against electromagnetic influence (EMR) of radio electronic means (REM) of strategic energy facilities (object of protection) is becoming important.

The REM failure rate of the object of protection is one of the highest in relation to other systems of efficiency.
The reasons for such failures, which lead to the failure or complete failure of REM, depend on insufficient security and non-compliance with the requirements for protection against the effects of strong EMR.

The external influence of EMR can include electromagnetic processes associated with the operation and / or disturbances in the operation of other technical electronic means of automation, technological equipment of the object of protection, as well as natural phenomena and actions of personnel that impair the quality of automation systems.

Types of electromagnetic interference that affect the REM of the object of protection [1-12]:

discharges of static electricity on the REM case, controls and external shields of cables;

nanosecond pulse interference in information circles and power supply coming from external sources of unintentional influence and possible terrorist means of electromagnetic influence;

magnetic fields of industrial frequency and others.

The object of protection is a complex structure, occupies a large area, has electrical connections with power systems, contains automated control, relay protection, alarms and others. All these components are exposed to various external and internal electromagnetic influences in normal and emergency cases.

The main reasons for this impact are: 
Oleksandr Akimov et al., International Journal of Emerging Trends in Engineering Research, 8(9), September 2020, $6214-6219$

destructive influence of terrorist means of electromagnetic influence on the REM of the object of protection;

lightning strikes directly on the object of protection, connecting lines or near them;

switching processes on the high voltage side as a result of scheduled switching, emergency processes (short circuit, overlapping of insulation of power lines, switching, etc.);

switching processes on the low voltage side when the REM is on and off, having inductive circuits with current or capacitive devices with voltage;

the presence of devices that create strong electric and magnetic fields of industrial frequency;

the presence of powerful high-frequency communication devices, data transmission, etc .;

the presence of fluctuations in the frequency of higher harmonics;

discharges of static electricity.

From the large list of possible electromagnetic influences of natural, technogenic character or human, it is possible to allocate destructive influence by terrorist means of electromagnetic influence on REM of object of protection.

Today, time for the control of technological processes is increasingly using modern electronic components based on microprocessor technology.

The complexity of electrical circuits of power facilities, as well as the expansion of the use of microprocessor technology, which has much lower levels of operating voltage and currents compared to common technology (electromechanical relays, contactors, electricity meters, etc.), and hence lower thresholds noise immunity, exacerbate the problems of protection against EMR. Operation of microprocessor technology in conditions of powerful electric and magnetic fields is a characteristic feature of modern energy facilities.

One of the most important issues that needs to be addressed to ensure the safety and reliability of operation of energy facilities - reduction (exclusion) of powerful electromagnetic effects on the normal functioning of REM, through the development of new means of protection using natural (plasma) environments.

\subsection{Problem analysis}

Analysis of the available literature indicates the great interest of scientists to study the processes of generating powerful EMR [1, 2, 3, 4, 5, 17, 21-23], the use of generators of powerful EMR including for influencing the element base of a radio electronic system. The results characterizing the state of the latest achievements in the field of protection of REM from EMR are presented in $[1,3,5,14,15,16,18-20]$. There are also many works devoted to traditional methods and means of protecting radio electronic devices against the effects of microwave radiation (MVR) [1,2]. Recently, there have been publications devoted to the use of radioisotope technologies for the protection of radio-electronic devices from exposure to electromagnetic radiation, which are nature-like [5, 11-14].

The nature of these technologies is associated with the use of reflecting and absorbing properties of plasma, which is the most common state of matter. Also associated with the use of properties of lightning, as a discharge in air, which in the first approximation can be used to create a highly conductive state of air in the holes in the slots of the housing-screens to protect against powerful electromagnetic radiation by breakdown and further energy removal of electromagnetic radiation.

At the same time, there are no mathematical models for describing the modified electrophysical properties of a solid-state plasma medium with hexaferrite elements.

The aim of research is development of a model of combined solid plasma material for the protection of radio-electronic means of optical and radio radiation.

\section{MAin Material}

Consider from a general standpoint approaches to determining the requirements for REM protection. To do this, we present REM in the form of a generalized model taking into account the state of operation.

According to the proposed generalized models of REM, we establish the relationship between the means and conditions of influence and REM [5, 22-25].

Given the main purpose of REM, as a general criterion for assessing its effectiveness, we will use the probability of performing a functional task in terms of possible influences. Based on this, taking into account the state of normal operation and reliability of the REM element base, we present in the form:

$$
\mathrm{P}_{\mathrm{B} \Phi 3}=\mathrm{f}\left(\mathrm{P}_{\mathrm{H} \Phi} ; \mathrm{P}_{\mathrm{H}} ; \mathrm{P}_{\mathrm{EMR}} ; \mathrm{P}_{\mathrm{MY}} ; \mathrm{P}_{\Pi}\right),
$$

where $P_{H \Phi}$ - the probability of normal REM operation;

$P_{H}$ - the probability of failure of REM;

$P_{B \Phi 3}$ - the probability of a terrorist REM;

$P_{M Y}$ - probability of influence of meteorological conditions;

$P_{H B \Pi}$ - the likelihood of unintentional interference. 
Assuming that REM operates only by terrorist means of electromagnetic influence, $P_{B \Phi 3}$ will be determined by the spatial and energy characteristics of terrorist means of electromagnetic influence. Based on this $P_{B \Phi 3}$ write in the form:

$$
\mathrm{P}_{\mathrm{B} \Phi 3}=\mathrm{f}\left(\Pi_{{ }_{\text {En }}}\right),
$$

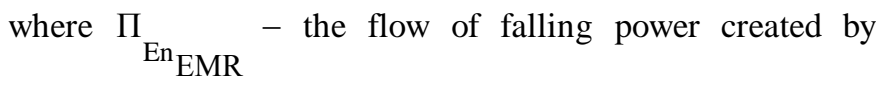
terrorist means of electromagnetic influence.

Functional damage to REM is carried out under the following condition

$$
\Pi_{\mathrm{En}_{\mathrm{EMR}}} \geq \Pi_{\Pi},
$$

where $\Pi_{\Pi}$ - the threshold value of the incident power flow at which the functional lesion of the REM.

Considering (3) $P_{B \Phi 3}$ under the influence of terrorist means of electromagnetic influence will be determined as follows:

$$
\mathrm{P}_{\mathrm{B} \Phi 3}=\mathrm{P}\left(\Pi_{\mathrm{En}_{\mathrm{EMR}}} \leq \Pi_{\Pi}\right) .
$$

Taking into account the distance $\mathrm{R}$ between REM and terrorist means of electromagnetic influence, the attenuation of EMR energy during the propagation in space of the power of terrorist means of electromagnetic influence, the pulse duration of EMR $\tau_{\mathrm{i}}$ falling power flow $\mathrm{P}_{\text {radiation }}$ at the input of REM will be presented as:

for radio frequency exposure of undirected action

$$
\Pi_{\Pi}=\kappa_{\mathrm{B}} \frac{\mathrm{P}_{\text {radiation }} \tau_{\mathrm{i}} \mathrm{G}}{4 \pi \mathrm{R}^{2}} \mathrm{e}^{-\alpha \mathrm{R}},
$$

where $\mathrm{P}_{\text {radiation }} \tau_{\mathrm{i}}=\mathrm{W}_{\text {radiation }}$ - the radiation energy of a pulsed generator of terrorist means of electromagnetic influence, which is determined by the power and duration of the radiation pulse, respectively;

$G$ - the gain of the antenna of the generator of terrorist means of electromagnetic influence;

$\alpha$ - linear attenuation coefficient of EMR in the propagation path;

$R$ - propagation distance;
$\kappa_{B}-$ EMR utilization factor;

for optical exposure

$$
\Pi_{\Pi}=\mathrm{K}_{\mathrm{B}} \frac{\mathrm{W}_{\text {radiation }}}{\Omega \mathrm{R}^{2}} \mathrm{e}^{-\alpha \mathrm{R}} .
$$

Taking into account the EMR shielding in accordance with (2), (3), (5) we present (4) as follows:

for radio frequency exposure of undirected action $\mathrm{P}_{\mathrm{B \Phi} 3}=\mathrm{P}\left(\Pi_{\mathrm{En}} \leq \mathrm{K}_{\mathrm{B}} \frac{\mathrm{P}_{\text {radiation }} \tau_{\mathrm{i}} \mathrm{G}}{4 \pi \mathrm{R}^{2}} \mathrm{e}^{-\alpha \mathrm{R}} 10^{-0.1 \mathrm{~K}_{\mathrm{E}}}\right)$.

for optical exposure

$$
\mathrm{P}_{\mathrm{B} \Phi 3}=\mathrm{P}\left(\Pi_{\mathrm{BX}} \leq \mathrm{K}_{\mathrm{B}} \frac{\mathrm{W}_{\text {radiation }}}{\Omega \mathrm{R}^{2}} \mathrm{e}^{-\mathrm{\alpha R}} 10^{-0.1 \mathrm{~K}_{\mathrm{E}}}\right) .
$$

Expressions (7), (8) allow to determine the distance at which the functional defeat of terrorist means of electromagnetic influence with the corresponding energy parameters of a REM depending on the stability of its element base, which determines the threshold value of the incident power flux at which the functional REM damage, as well as the parameters of shielding means of REM protection.

$$
\mathrm{R}_{\max }=\sqrt{\frac{\mathrm{W}_{\text {radiation }} \mathrm{K}_{\mathrm{B}}}{\Pi_{\Pi} \Omega} \mathrm{e}^{-\alpha \mathrm{R}} 10^{-0.1 \mathrm{~K}_{\mathrm{E}}}} .
$$

Consider that

$$
\Pi_{\mathrm{BX}}=[\mathrm{E} \times \mathrm{H}]=\frac{\mathrm{E}^{2}}{\mathrm{Z}}
$$

where $Z=377 \Omega$.

Then, taking into account (5), we write:

$$
\mathrm{R}_{\max }=\sqrt{\frac{30 \mathrm{P}_{\mathrm{radiation}} \mathrm{GK}_{\mathrm{B}}}{\mathrm{E}_{\Pi} \tau_{\mathrm{i}}^{2}} \mathrm{e}^{-\mathrm{- \alpha R}} 10^{-0.05 K_{\mathrm{E}}}}
$$

Let's define the basic requirements to means of protection, proceeding from the most general assumptions concerning characteristics of objects of protection and terrorist means of electromagnetic influence, radio frequency and optical influence given in literature. [1-7, 24-27].

Taking into account the pulse duration of EMR, which lies in the range from units - tens of nanoseconds to $10^{-18} \mathrm{~s}$, the energy at which degradation phenomena occur in the most sensitive elements $10^{-4} \ldots 10^{-8} \mathrm{~J}$ and the laser energy at which the protective material will evaporate $\left(0,2 \ldots .2,5 \mathrm{~J} / \mathrm{sm}^{2}\right.$ at $\left.\tau_{\mathrm{i}}=10^{-9} \mathrm{~s}\right)$, 
Oleksandr Akimov et al., International Journal of Emerging Trends in Engineering Research, 8(9), September 2020, $6214-6219$

as well as the magnitude of the power of terrorist means of electromagnetic influence from 1 to $100 \mathrm{GW}$ and more [7-14], REM protection must be carried out taking into account the principles of construction of REM themselves, their purpose and a wide range of EMR characteristics, which can lead to functional damage to REM.

Recently, a number of factors and trends have been identified that directly or indirectly lead to a decrease in the effectiveness of the use of devices and means of protection of REM from EMR, which include the following:

expanding the range of tasks to be solved by disabling REM;

sudden application;

reduction of quality requirements for information on REM characteristics;

expansion of types and further improvement of terrorist means of electromagnetic influence, which is aimed at increasing the energy of electromagnetic influence and reducing the pulse duration $\left(10^{-9} \ldots 10^{-18} \mathrm{~s}\right)$;

Due to these factors, devices and means of protection of REM from EMR must provide in the ultra-wide frequency band a level of shielding at which the value of EMR energy that will pass to the REM elements will not exceed when degradation effects occur (not more $10^{-8} \mathrm{~J}$ ), and reflection of laser energy, which will not evaporate the protective material $(>0,2 \ldots 2,5$ $\mathrm{J} / \mathrm{sm}^{2}$ at $\left.\tau_{\mathrm{i}}=10^{-9} \mathrm{~s}\right)$.

When substantiating the requirements it is necessary to take into account the following:

based on the conditions of placement on air objects, means and devices of protection should occupy an insignificant part of the total weight and volume taken away under payload ( $(20 \ldots 40)$ $\left.\mathrm{g} / \mathrm{m}^{2}\right)$;

given the tendency to increase the flight speed of aeroballistic objects to $1 \mathrm{~km} / \mathrm{s}$ and more, the characteristics of the protective coating should not significantly depend on the flight parameters, which are due primarily to the temperature of the coating (up to 2000K) [1-3, 28,2 9], means of protection should not severely limit the possibilities of flight conditions; in addition, protection must be repeated and without prior training;

in view of the possible rapid change of location of EMR devices, devices and means of protection should not require preparation for their use.

The creation of devices and means of protection of REM, taking into account the main characteristics, features of application and functioning of terrorist means of electromagnetic influence, should be aimed at the optimal combination and implementation of the following principles:

no influence on the process of REM functioning when interacting with EMR;

instant response to EMR (ensuring the required speed taking into account the duration of the EMR pulse);

energy independence or minimum allowable energy consumption;

reusability;

invariability or permissible increase of weight and dimensional characteristics of objects of protection;

practical implementation and possibility of application on both ground and airborne objects.

The implementation of these principles is aimed at improving the effectiveness of REM protection against destructive unintentional EMR and the impact of terrorist means of electromagnetic influence, to the maximum allowable, which will ensure the performance of the functional task of REM $P_{B \Phi 3} \approx 1$.

\section{CONCLUSION}

A generalized stochastic model of REM under conditions of electromagnetic terrorism has been developed.

The basic calculation ratios for the determination of the ways and composition of the means of protection, depending on the energy parameters of the means of electromagnetic terrorism, have been given.

The criterion for estimating the effectiveness of REM functioning under conditions of electromagnetic terrorism has been developed, namely, taking into account the stochastic model of the REM functioning process, it has been proposed to use the probability of fulfilling the task in the conditions of possible influences.

The main requirements for the protection of radio-electronic equipment of energetic objects from the terroristic influence by electromagnetic radiation have been formulated.

\section{REFERENCES}

1 M. Iasechko. Plasma technologies for the protection of radio electronic means from exposure to high-power electromagnetic radiations with ultrashort pulse duration, Proceedings of the 1-st Annual Conference, 
Oleksandr Akimov et al., International Journal of Emerging Trends in Engineering Research, 8(9), September 2020, 6214 - 6219

Tallinn, Estonia, 2017, pp. 18-21. doi: 10.21303/2585-6847.2017.00480.

2 O. Turinskyi1, M. Iasechko, V. Larin, T. Prokopenko, O. Kolmohorov, O. Salash, V. Tarshyn and Yu. Dziubenko. Determination of requirements for the protection of radio-electronicequipment from the terroristic influence by electromagnetic radiation, IJETER, 8(4), 2020, pp. 1333 - 1334. doi: 10.30534/ijeter/2020/64842020.

3 M. Iasechko, V. Larin, D. Maksiuta, S.Bazilo and I. Sharapa. The method of determining the probability of affection of the semiconductor elements under the influence of the multifrequency space-time signals, Journal of Critical Reviews, 7(9), 2020, pp. 569 - 571. doi: 10.31838/jcr.07.09.113.

4 O. G. Sytenko. Electromagnetic plasma fluctuations, KhGPU, Ukraine, Kharkiv, 1965, pp. 1-183.

5 S.A.Gutsev, A.A. Kudryavtsev, R.Yu. Zamchiy, V.I. Demidov, and V.I. Kolobov. Diagnostics and modeling of ashort (without positive column) glow discharge in helium with nonlocal plasma, Proc. 40th European Physical Society Conference on Plasma Physics, Finland, 2013, N 06.502.

6 M.M. Iasechko, and O.M. Sotnikov. Advanced technologies of radio electronic equipment (means) protection from powerful electromagnetic radiations with ultra short duration of pulses exposure, Published by Izdevnieciba Baltija Publishing, Collective monograph, Riga, 2018, pp.356-385.

7 M. Iasechko, N. Sachaniuk-Kavets'ka, V.Kostrytsia, V.Nikitchenko and S. Iasechko. The results of simulation of the process of occurrence of damages to the semiconductor elements under the influence of multi-frequency signals of short duration, Journal of Critical Reviews, 7(12), 2020, pp. 109 - 112. doi:10.31838/jcr.07.13.18.

8 O.Skoblikov and V. Knyazyev. Properties of Conductive Shells Exposed to Electromagnetic Impulse of Lightning, International Conference on Lightning Protection (ICLP'2012), Vienna, Austrian, 2012, pp. 1-8.

9 H. Khudov, S. Glukhov, O. Maistrenko, A. Fedorov, A. Andriienko, O. Koplik, The Method of ADS-B Receiver Systems Synchronization Using MLAT Technologies in the Course of Radar Control of Air Environment, International Journal of Emerging Trends in Engineering Research, Vol. 8. № 5, 2020, pp. 1946-1951. doi:10.30534/ijeter/2020/78852020.10.

10 H. Khudov, O. Makoveychuk, I. Khizhnyak, I. Yuzova , A. Irkha, and V. Khudov. The Mosaic Sustainable Marker Model for Augmented Reality Systems, International Journal of Advanced Trends in Computer Science and Engineering, Vol. 9. № 1, 2020, pp. 637-642. doi:10.30534/ijatcse/2020/89912020.

11 I. Ruban, H. Khudov, O. Makoveychuk, I. Khizhnyak, V. Khudov, and V. Lishchenko The model and the method for forming a mosaic sustainable marker of augmented reality. 2020 IEEE 15 th Inter. Conf. on
Advanced Trends in Radioelectronics, Telecommunications and Engineering (TCSET), February 2020 . doi:10.1109/TCSET49122.2020.235463.

pp. 402-406.

12 M. Iasechko, M. Kolmykov, V. Larin, S.Bazilo, H. Lyashenko, P. Kravchenko, N. Polianova and I. Sharapa. Criteria for performing breakthroughs in the holes of radio electronic means under the influence of electromagnetic radiation, ARPN Journal of Engineering and Applied Sciences, 15(12), 2020, pp. 1380 - 1384.

13 O. Sotnikov, M. Iasechko, V. Larin, O. Ochkurenko, and D.Maksiuta. The model of a medium for creation of electric hermetic screens of the radio electronic means, IJATCSE. 8(2), 2019, pp. 300-304. doi:10.30534/IJATCSE/2019/32822019.

14 M. Iasechko, O. Tymochko, Y. Shapran, I. Trofymenko, D. Maksiuta, and Y. Sytnyk. Loss definition of charged particles in the discharge gap of the opening of the box-screens during the formation of a highly conductive channel, IJATCSE. 8(1.3), 2019, pp. 1-9. doi: 10.30534/ijatcse/2019/0181.32019.

15 M. Iasechko, V. Larin, O. Ochkurenko, S. Salkutsan, L. Mikhailova, and O. Kozak. Formalized Model Descriptions Of Modified Solid-State Plasma-Like Materials To Protect Radio-Electronic Means From The Effects Of Electromagnetic Radiation, IJATCSE. 8(3), 2019, pp. 393-398. doi: 10.30534/ijatcse/2019/09832019.

16 M. Iasechko, V. Larin, O. Ochkurenko, A. Trystan, T.Voichenko, A. Trofymenko, and O. Sharabaiko. Determining the function of splitting the charged particles of the strongly ionized air environment in the openings of the case-screens of radioelectronic means, IJATCSE. 8(1.3), 2019, pp. 19-23. doi: 10.30534/ijatcse/2019/0481.32019.

17 M.M. Iasechko, and O.M. Sotnikov. Protecting of radio electronic facilities is from influence of powerful electromagnetic radiation, Published by Izdevnieciba Baltija Publishing, Collective monograph, Riga, 2019, pp.283-299.

18 A. Syrotenko, O. Sotnikov M. Iasechko, V. Larin, S.Iasechko O. Ochkurenko, and A. Volkov. Model of Combined Solid Plasma Material for the Protection of Radio-Electronic Means of Optical and Radio Radiation, IJATCSE, 8(4), 2019, pp. 1241 - 1247. doi:10.30534/ijatcse/2019/33842019.

19 V. Gurevich. Electromagnetic Terrorism: New Hazards. - Electrical Engineering and Electromechanics, N 4, 2005.

$20 \mathrm{Yu}$. P. Reiser. Breakdown and heating of gases under the action of laser beam, The successes of the physical sciences, 1965.

21 A.V. Bobylev, and V.A. Chuyanov. On the numerical solution of the Landau kinetic equation, Journal of Computational Mathematics and Mathematical Physics, $T$. 16. № 2, 1977, pp. $407-416$. 
22 O. Turinskyi, M. Burdin, M. Iasechko, V. Larin, Y. Gnusov, D. Ikaev, V. Borysenko, and V. Manoylo. Protection of board radioelectronic equipment from the destructive powerful electromagnetic radiation with the use of natural technologies, IJETER, 7(11), 2019, pp. 542 - 548. doi: 10.30534/ijeter/2019/2371120 19.

23 M. Iasechko, V. Larin, D. Maksiuta, O. Ochkurenko, I. Krasnoshapka, Y.Samsonov, H. Lyashenko, A.Zinchenko, and R.Vozniak. Model description of the modified solid state plasma material for electromagnetic radiation protection, IJETER, 7(10), 2019, pp. $376 \quad-\quad 382 . \quad$ doi: 10.30534/ijeter/2019/027102019.

24 O. Turinskyi, M. Iasechko, V. Larin, D. Dulenko, V. Kravchenko, O. Golubenko, D.Sorokin, and O. Zolotukhin. Model and development of plasma technology for the protection ofradio-electronic means of laser emission, IJATCSE. 8(5), 2019, pp. 2429-2433. doi:10.30534/IJATCSE/2019/85852019.

25 M.Iasechko, Y. Gnusov, I. Manzhai, O. Uhrovetskyi, V.Manoylo, A. Iesipov, O. Zaitsev, M. Volk, and O. Vovk. Determination of requirements for the protection of radio-electronicequipment from the terroristic influence by electromagnetic radiation, IJETER, 7(12), 2019, pp. 772 - 777. doi: 10.30534/ijeter/2019/077122019.

26 O. Akimov, V.Troschinsky, M.Karpa, V.Ventsel, L. Akimova. International experience of public administration in the area of national security. Journal of Legal, Ethical and Regulatory Issues, Volume 23, Issue 3, 2020.

27 L.Shytyk, A. Akimova. Ways of Transferring the Internal Speech of Characters: Psycholinguistic Projection. Psycholinguistics. Pereiaslav-Khmelnytskyi Hryhorii Skovoroda State Pedagogikal University. 27 (2), 2020, pp. 361-384.

28 O.Akimov, M.Karpa, O.Parkhomenko-Kutsevil, V.Kupriichuk, A. Omarov. Entrepreneurship education of the formation of the e-commerce managers professional qualities. Journal of Entrepreneurship Education, 23(S1). 2020.

29 I.Panasiuk, L. Akimova, O. Kuznietsova. Modelling and Simulation of the Thermal Performance of Metal Framed Walls. IEEE International Conference on Advanced Trends in Information Theory, ATIT 2019 Proceedings. 